\title{
Optical Response and Photovoltaic Performance of Organic Solar Cells Based on DH6T:Alq3 Active Layer
}

\author{
Fahmi Fariq Muhammad ${ }^{\mathrm{a},{ }^{*}}$, Abdulkader Jaleel Muhammad $^{\mathrm{b}}$ and Khaulah Sulaiman ${ }^{\mathrm{c}}$ \\ ${ }^{a}$ Soft Materials and Devices Laboratory, Department of Physics, Faculty of Science and Health, Koya \\ University, Koya, Kurdistan Region, Iraq \\ ${ }^{b}$ Department of Physics, College of Science, University of Kirkuk, Kirkuk, Iraq \\ 'Low Dimensional Materials Research Center, Department of Physics, Faculty of Science, University of \\ Malaya, 50603 Kuala Lumpur, Malaysia
}

\begin{abstract}
This research work reports on the optical and photovoltaic performance of dihexyl-sexithiophene (DH6T) doped with various molar percentages of tris-8-hydroxyquinolinate aluminium (Alq3) dissolved in chloroform/hexane cosolvent. Films of $\mathrm{DH} \mathrm{T}_{(1-\mathrm{x})} \mathrm{Alq}_{(\mathrm{x})}$ composite have been produced by casting technique aiming at investigating their absorption edge energies $\left(E_{a b s}\right)$ and hence identifying the optimum content of Alq3. It was found that by introducing a controlled amount of Alq3, the value of $E_{\text {abs }}$ can be tuned from $2.69 \mathrm{eV}$ to $1.76 \mathrm{eV}$. An empirical equation was derived to fit the obtained experimental data, by which an optimum $E_{a b s}$ at molar concentration of $(x \approx 25 \%)$ was predicted. Finally, organic solar cells based on the optimum active layer content were fabricated and tested. Comparably, it was observed that the photovoltaic performance of the DH6T:Alq3 based devices is much better than that achieved for the DH6T:PCBM based ones. Efficiency and fill factor for the devices based on $\mathrm{DH}_{6} \mathrm{~T}_{(0.75)} \mathrm{Alq}_{(0.25)}$ active layer were found to be $0.22 \%$ and $26.5 \%$, respectively, while those for DH6T:PCBM based devices were about $0.01 \%$ and $24 \%$, respectively.
\end{abstract}

Keywords: Alq3, DH6T, Organic composite, Doping, Absorption edge, organic solar cells.

\section{INTRODUCTION}

Organic semiconductors have been receiving great deal of attention due to their easy processing, tuneable optical properties and higher flexibility compared to those of inorganic ones [1-4]. Thiophene based materials have been the most studied organic semiconductors showing promising future for certain applications like diodes, transistors and photovoltaic cells [5-10]. Despite of these appealing applications, much effort is still needed for an in-depth understanding of the physical mechanisms, e.g. charge carrier generation, transport and recombination processes [5, 11]. Oligothiophenes, either unsubstituted, or substituted by alkyl chains as a pendent group in the $\beta$ position or as end groups in the $\alpha, \omega$ positions have been investigated in literature [12-15]. It was claiming that possible substitution of $\mathrm{H}$ atoms on the thiophene rings with properly designed chemical groups allows engineering their electronic and optical responses $[16,17]$. Upon the addition of hexyl side chains to $\alpha$-sexithiophene main molecule, dihexyl-sexithiophene (DH6T) is obtained with higher solubility and field-effect mobility as high as $1 \mathrm{~cm}^{2} / \mathrm{V}$.s $[18,19]$. Doping DH6T with a proper material will

*Address correspondence to this author at the Soft Materials and Devices Laboratory, Department of Physics, Faculty of Science and Health, Koya University, Koya, Kurdistan Region, Iraq; Tel: + 974-7701935331; E-mail: fahmi982@gmail.com, fahmi.fariq@koyauniversity.org diversify its optical and electrical properties for wider areas of application like field effect transistors, diodes and solar cells. It was reported that synthesized polythiophene containing complexes of 8hydroxyquinoline with $\mathrm{Zn}(\mathrm{II}), \mathrm{Cu}(\mathrm{II})$ and $\mathrm{Eu}(\mathrm{III})$ in the side chains can show novel thermal stability and good devices performance when they are applied in dye sensitized solar cells [20]. Based on this improvement and previous results obtained for tris(8hydroxyquinoline) aluminum, Alq3 [21], we anticipate that the physical properties of DH6T might be enhanced by incorporating Alq3 molecules. Hence, in this work we investigate the optical absorption and photovoltaic properties of tris (8-hydroxyquinolinate) aluminum (Alq3) doped dihexyl-sexithiophene (DH6T) in different molar ratios aiming at defining the impact of Alq3 admixture on the absorption edge energy $\left(E_{a b s}\right)$ of DH6T. Additionally, an empirical formula is proposed to estimate the optimum dopant ratio, at which the minimum $E_{a b s}$ can be achieved. This becomes a possible support to identify the optimum condition of the active layer components in a required optoelectronic device before its fabrication is carried out.

\section{MATERIALS AND METHODS}

Dihexyl-sexithiophene (DH6T) and tris-8hydroxyquinolinate aluminum (Alq3) were purchased from Sigma-Aldrich in powder form and used as 

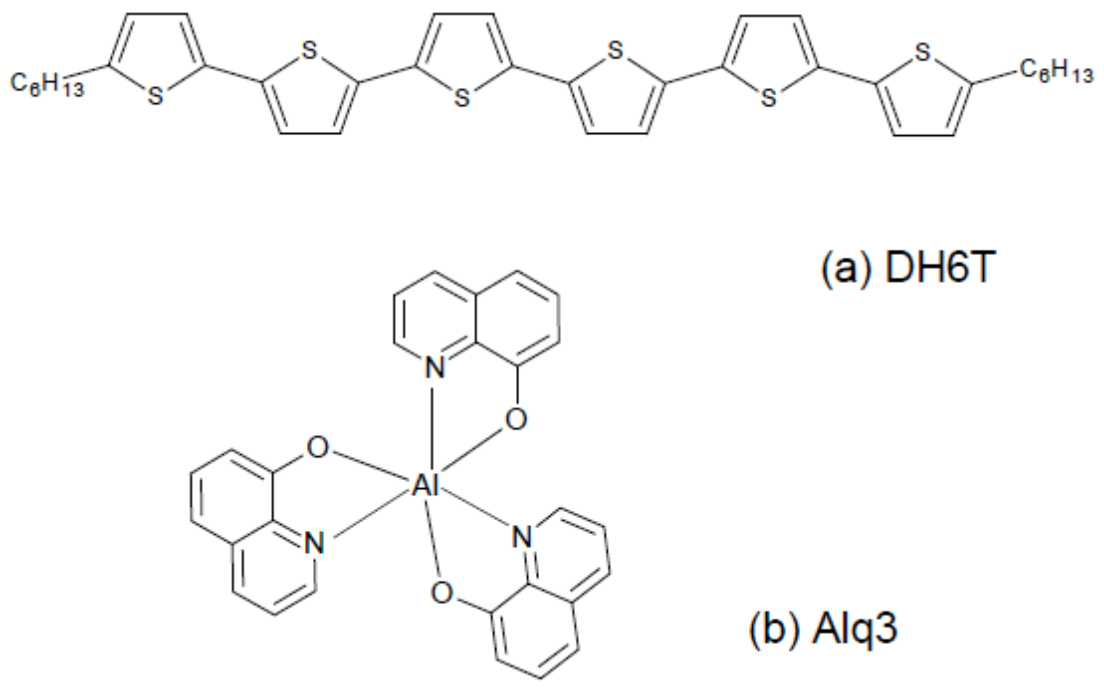

(a) DH6T

Figure 1: The molecular structure of (a) DH6T host and (b) Alq3 admixture.

received. The chemical structures of $\mathrm{DH} 6 \mathrm{~T}$ and Alq3 with linear molecular formula of $\mathrm{C}_{36} \mathrm{H}_{38} \mathrm{~S}_{6}$ and $\mathrm{Al}\left(\mathrm{C}_{9} \mathrm{H}_{6} \mathrm{NO}\right)_{3}$ respectively are shown in Figure 1 . Chloroform and hexane co-solvent (1:1) was used to dissolve the raw materials and to obtain solutions of $\mathrm{DH}_{61} \mathrm{~T}_{(1-\mathrm{x})} \mathrm{Alq}_{(\mathrm{x})}$ mixture. The $\mathrm{DH6T}_{(1-\mathrm{x})} \mathrm{Alq}_{(\mathrm{x})}$ mixtures with different molar percentages of Alq3 were dissolved in $2 \mathrm{ml}$ of chloroform/hexane co-solvent. The prepared solutions with concentration of $5 \mathrm{mg} / \mathrm{ml}$ were stirred at $500 \mathrm{rpm}$ for about 72 hours on the magnetic stirrer. Films of $\mathrm{DH}_{6 \mathrm{~T}_{(1-x)}} \mathrm{Alq}_{(\mathrm{x})}$ composite were coated onto the pre-cleaned quartz substrates by casting technique. The quartz slides were cleaned ultrasonically with Deacon ${ }^{\circledR}$ Neutracon foam solution for 15 minutes followed by rinsing in acetone, ethanol and distilled water for 10 minute in an ultrasonic bath, respectively. Finally, they were dried thoroughly by blowing nitrogen gas.

Optical absorption spectra for the films were recorded at room temperature using Jasco V-570 UVVis-NIR spectrophotometer in the wavelength range from 250 to $1250 \mathrm{~nm}$. The thickness of the films were determined using KLA Tencor P-6 surface profilometer, that is by scratching each film in three different regions across its surface, then taking the average of the measurements. The deposited films were varied from $5 \mu \mathrm{m}$ to $7 \mu \mathrm{m}$ in thickness. X-ray diffractometer (Bruker AXS) using $\mathrm{Cu} \mathrm{K}_{\alpha}$ radiation of wavelength $\lambda=1.5406$ $A^{\circ}$ as a source was used to measure the XRD patterns and confirm the structural nature of the composite films. ITO coated glass substrates $(\mathrm{H}$. W. Sands Co., Ltd.) with sheet resistance of $\sim 10 \Omega / \mathrm{sq}$ were etched and cleaned, then used to fabricate the organic solar cell devices. Desired ITO pattern was created via a wet etching process by immersing the substrates in a bath of hydrochloric acid and distilled water $(0.4: 1)$ etchant, then agitated for 15 minute at temperature of $60{ }^{\circ} \mathrm{C}$. The etching precision was assured under the KLA Tensor P-6 surface profiler instrument surface scanning measurement. The PEDOT:PSS $(\mathrm{H}$. C. Starck, Baytron P VPAI 4033) layers were spin-coated onto the ITO at $3000 \mathrm{rpm}$ for $20 \mathrm{sec}$, then baked at 130 ${ }^{\circ} \mathrm{C}$ for $5 \mathrm{~min}$ to get the thickness of $\sim 35 \mathrm{~nm}$. Afterwards, solution of $\mathrm{DH} \mathrm{T}_{(0.75)} \mathrm{Alq}_{(0.25)}$ was spin coated onto the PEDOT:PSS film to get a thickness of about $200 \mathrm{~nm}$. Finally, aluminum $(50 \mathrm{~nm})$ was thermally evaporated onto the PCBM layer in a vacuum at $10^{-5} \mathrm{mbar}$ through a metal mask to give an active area of $14 \mathrm{~mm}^{2}(2 \mathrm{x}$ $\left.7 \mathrm{~mm}^{2}\right)$. The current density-voltage $(J-V)$ measurement was performed using a Keithley 236 instrument under $80 \mathrm{~mW} / \mathrm{cm}^{2}$ illumination from an Oriel solar simulator-model 67005 with an AM 1.5 G filter under ambient condition.

\section{RESULTS AND DISCUSSION}

Figure 2 shows the absorption spectra of DH6T, Alq3 and $\mathrm{DH}_{6} \mathrm{~T}_{(0.70)} \mathrm{Alq}_{(0.30)}$ films in the wavelength range from 300 to $1000 \mathrm{~nm}$, while the inset of figure depicts the XRD patterns of the investigated samples, in which they showed amorphous structure. The absorption coefficient $(\alpha)$ was calculated using $\alpha=2.303 \mathrm{~A} / \mathrm{t}$ where, $A$ is the absorbance of the film and $t$ its thickness. It was seen that in the wavelength range from 250 to $450 \mathrm{~nm}$, the absorption coefficient of Alq3 is higher than those of $30 \%$ Alq3 doped composite and pure DH6T. While for most of the optoelectronic 
applications a large amount of light absorption is required, it is worthy to mention that in a specific range of wavelength $(250-450 \mathrm{~nm})$, the absorption coefficient of the composite films has increased when Alq3 molecules was added into the pure DH6T.

Optical absorption is an important tool for investigating the electronic structure, band gap $\left(E_{g}\right)$ or absorption edge energies $\left(E_{a b s}\right)$ of the electronic materials [22-24]. Electromagnetic radiation of photons can be absorbed by solids in variety of ways. The photon energy can excite lattice vibrations to create phonons, excite electrons to generate excitons (bounded electron-hole pairs) or polarons (electrons or holes bound to a deformed potential), and/or promote electrons from the valence band (the highest occupied molecular orbital, HOMO) to the conduction band (the lowest unoccupied molecular orbital, LUMO) inside the organic semiconductor material. For the last mechanism to be happened, the energy of the incident photon must be larger than the absorption edge energy, $E_{a b s}$ of the material. Thus, the coefficient that describes the absorption is strongly depended on the photon energy (or wavelength). For the materials investigated in this work, conjugated pi-orbitals play an important role in shaping the electronic properties. The bonds inside the molecule involve a mixture of strong $\delta$ - type and $\pi$-type, while the intermolecular bonds are Vander Walls or hydrogen like bond. The electrons in the $\pi$-type bonds are somewhat delocalized and free to move inside the molecular chains and ligands of DH6T and Alq3, respectively.
The absorption coefficient is related to the photons energy $(h v)$ according to the equation [25]:

$\alpha h v=B\left(h v-E_{o}\right)^{n}$

Where, $B$ is a factor depends in general on the density of states and transition probability, neither depends on photon energy, nor the optical band gap, $E_{o}$. In the equation, $n=1 / 2$ for the direct and $n=2$ for indirect allowed transitions. The value of $n$ has been deduced for our films by fitting the correlated photon energies with the absorption coefficient using MATLAB curve fitting. The best fit has been achieved at $n \sim 0.5$. Graphs of $(\alpha E)^{2}$ versus photon energy $E=h v$ for the $\mathrm{DH} \mathrm{T}_{(1-\mathrm{x})} \mathrm{Alq}_{(\mathrm{x})}$ films were plotted, as shown in Figure 3. Extrapolation of these plots to zero $(\alpha E)^{2}$ axis gives the fundamental absorption edge energy $\left(E_{a b s}\right)$. The estimated values of $E_{a b s}$ are tabulated in Table 1.

The slopes in Figure $\mathbf{3}$ are measures of $A_{o}$ and the strength of the absorption. By choosing the curve of pure DH6T as an example, we can obviously note that there are three regions showing variation of slopes. The region above the photon energy of $4.0 \mathrm{eV}$, (the high energy region) is the one which obeys the mechanism alluded by Equation 1, that is direct allowed transition between HOMO and LUMO levels. This is a transition from $\pi \rightarrow \pi^{*}$ bands [26] within the energy levels of DH6T molecule. Therefore, the value of fundamental absorption edge energy, $E_{a b s}$ given in Table 1 is deduced in this region. The second region (middle energy) spans from the photon energy of 4.0 $\mathrm{eV}$ downwards to nearly $2.0 \mathrm{eV}$. This region is usually

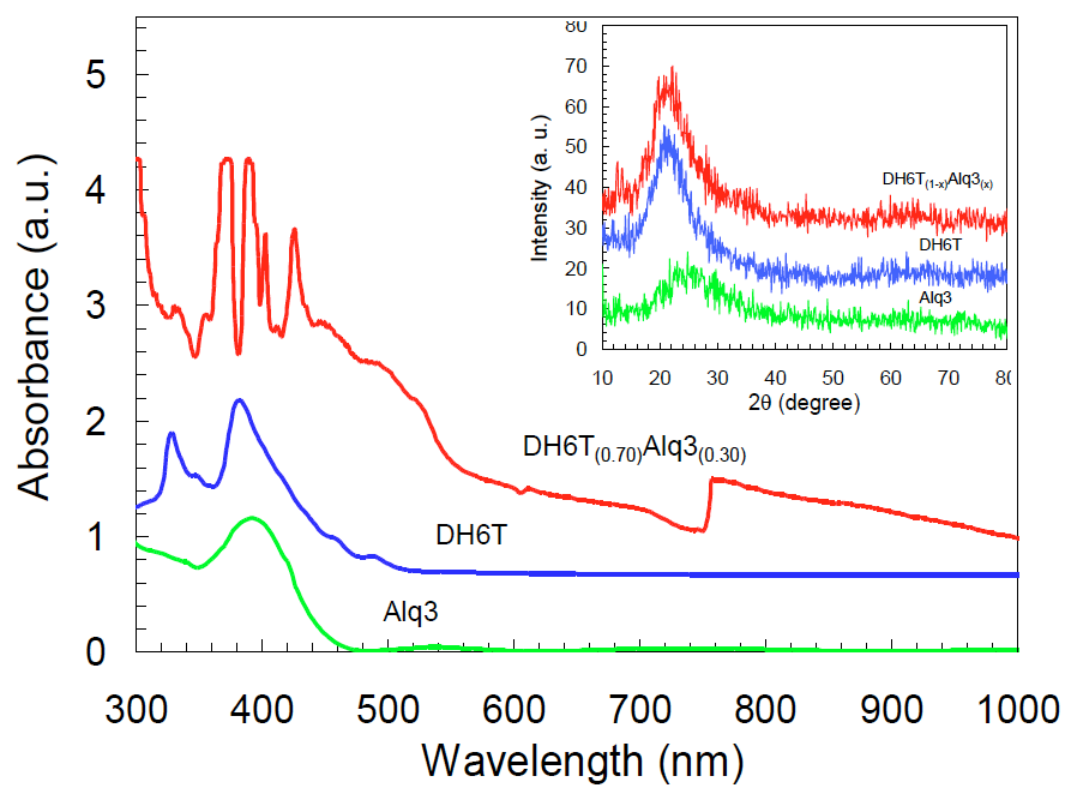

Figure 2: Absorbance spectra of $\mathrm{DH} 6 \mathrm{~T}, \mathrm{Alq} 3$, and $\mathrm{DH} \mathrm{T}_{(0.70)} \mathrm{Alq}_{(0.30)}$ films. Inset of the figure shows the $\mathrm{XRD}$ pattern of the films under investigation. 


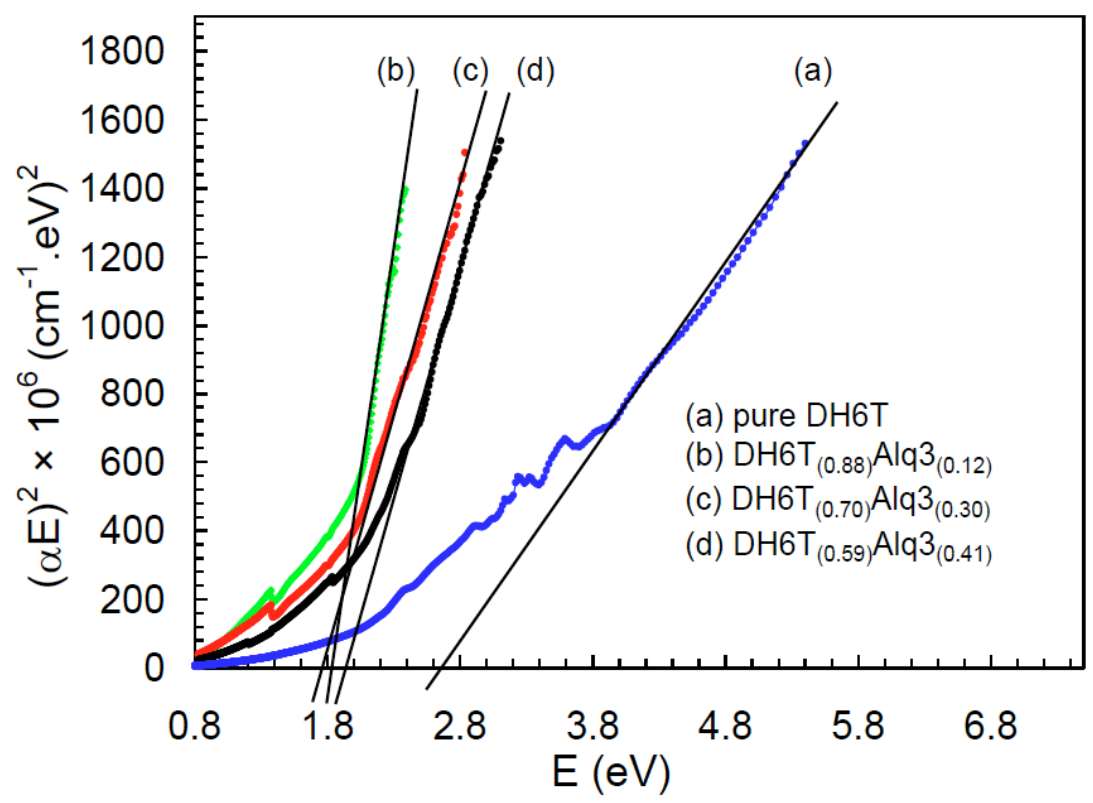

Figure 3: Plots of $(\alpha E)^{2}$ against photon energy for the films of pure $\mathrm{DH} 6 \mathrm{~T}$ and $\left.\mathrm{DH}_{6} \mathrm{~T}_{(1-\mathrm{x})}\right) \mathrm{Alq}_{(\mathrm{x})}$ composites.

Table 1: Estimated Values of the Absorption Edge Energy, $E_{a b s}$ and Sub-Energy Levels of $E_{01}$ and $E_{02}$.

\begin{tabular}{|c|c|c|c|}
\hline Film composition & $E_{\text {abs }}(\mathrm{eV})$ & $E_{\text {o1 }}(\mathrm{eV})$ & $E_{\text {o2 }}(\mathrm{eV})$ \\
\hline \hline Pure DH6T & 2.69 & 1.7 & 0.8 \\
\hline $\mathrm{DH6T}_{(0.88} \mathrm{Alq3}_{(0.12)}$ & 1.88 & 1.0 & 0.8 \\
\hline $\mathrm{DH6T}_{(0.7)} \mathrm{Alq3}_{(0.3)}$ & 1.76 & 1.0 & 0.8 \\
\hline $\mathrm{DH6T}_{(0.59)} \mathrm{Alq3}_{(0.41)}$ & 1.94 & 1.0 & 0.8 \\
\hline Pure Alq3 & 2.86 & - & - \\
\hline
\end{tabular}

named as "tail" in the literatures and frequently ascribed to the localized energy states below the band gap or to phonon assisted indirect transitions [27]. These localized states are usually generated due to the doping process and/or some sort of defects inside the semiconductor materials. The third region of the slope located below $2.0 \mathrm{eV}$ (low energy region). Since the films used in this investigation are not well-defined crystalline structures, as verified by the XRD pattern (see the inset of Figure 2), we are inclined to assume that both of the middle and low energy regions are due to the transitions between delocalized states of $\mathrm{HOMO}$ and LUMO levels.

Inspired by the results obtained from Figure 3, we invoke the idea that a sequence of absorption levels each with its own energy might be involved in the process. So, Equation 1 can be generalized to take the following form:

$\alpha h v=\sum_{i}^{N} B_{i}\left(h v-E_{i}\right)^{n_{i}}$
Accordingly, plots of $(\alpha E)^{2}$ versus photon energy $E$ $=h v$ will exhibit regions with different slopes, and the intersection of extrapolated linear sub-regions will yield the values of the discrete absorption edge energies $E_{i}$, e.g. $E_{1}, E_{2} \ldots E_{N}$. Based on this interpretation, values of the absorption edge levels were deduced from the intercept of the respective regions of the plot (the low and medium regions), i.e., $E_{01}$ and $E_{o 2}$ in Table 1. It is instructive to note that the value of $E_{02}$, is approximately the same $(0.8 \mathrm{eV})$ for all the investigated samples (apart from the pure Alq3 sample which does not show the tail region). The value of $E_{01}$ is almost the same $(1.0 \mathrm{eV})$ for $\mathrm{DH}_{6 \mathrm{~T}}(1-\mathrm{x}) \mathrm{Alq} 3_{(\mathrm{x})}$ samples but with higher value $(1.7 \mathrm{eV})$ in pure $\mathrm{DH} 6 \mathrm{~T}$ sample.

The $E_{01}, E_{o 2}$, energy levels could be ascribed to the excitonic level localized at various sites of the DH6T molecule $\left(\mathrm{C}_{36} \mathrm{H}_{38} \mathrm{~S}_{6}\right)$. The $E_{01}$ excitons are probably of the Mott-Wanneir exciton type (weakly bound, somewhat mobile), while the $E_{02}$ excitons are probably of the Frenkel type (tightly bound, mostly localized at the site) [28]. Therefore, it is the only weakly bound 
exciton levels that are mostly affected by the presence of Alq3 in the DH6T host material, as in turn can provide the drastic change in the fundamental absorption edge energy $\left(E_{a b s}\right)$ of the $\mathrm{DH} \mathrm{T}_{(1-\mathrm{x})} \mathrm{Alq}_{(\mathrm{x})}$ films.

The results shown in Figure $\mathbf{3}$ indicate a measurable effect of adding Alq3 on the absorption edge energy, $E_{a b s}$ of $\mathrm{DH}_{6} \mathrm{~T}_{(1-\mathrm{x})} \mathrm{Alq}_{(\mathrm{x})}$ with molar concentrations of $12.4 \%, 29.8 \%$, and $41.4 \%$ for Alq3. It was seen that $E_{a b s}$ decreases with increasing concentration up to $29.8 \%$ then rises for higher concentration of $41.4 \%$. In order to describe this behaviour, an attempt was made to find a formula, which fits the experimental findings. In Figure 4, we display a plot of $E_{a b s}$ versus molar concentration of Alq3. The symbols represent the experimental data, while the continuous line represents the empirical formula. The fitted curve shown in Figure $\mathbf{4}$ corresponds to the following formula:

$E_{g}=E_{g 1}\left(\frac{1-x}{1+B x}\right)^{2}+E_{g 2}\left(\frac{(1+2 B) x}{1+2 B x}\right)^{2}$

Where, $\mathrm{B}$ is a numerical factor, $\mathrm{B}=1.6, E_{g 1}, E_{g 2}$, and $x$ denote to the absorption edge energies of pure DH6T host $\left(E_{g 1}=2.69 \mathrm{eV}\right)$, added Alq3 $\left(E_{g 2}=2.86 \mathrm{eV}\right)$, and the molar fraction of Alq3, respectively. It is clear from Figure 4 that Equation 3 can fit the experimental data very well. The decrease in $E_{a b s}$ within the range of $0 \%$ to $29.8 \%$ of Alq3 from $2.69 \mathrm{eV}$ to $1.76 \mathrm{eV}$ is attributed to the presence of intermolecular interactions between the DH6T chains and Alq3 ligands, where the aggregation of Alq3 molecules along the DH6T host becomes more prominent. The interaction may have either two effects; an increase in the conjugation length which is brought about by the reduction in the absorption edge energy (shifting towards longer wavelengths), and a general effect on the dielectric constant [29] of the material due to the added presence of ions such as, $\mathrm{O}, \mathrm{N}$, and Al. But, the magnitude of the change is not linear in terms of its dependence on concentration. It is clear that for the concentration ranging from $0 \%$ to $12.4 \%$ has caused the $E_{a b s}$ to decrease from 2.69 to $1.88 \mathrm{eV}$, (that is about $0.89 \mathrm{eV}$ ). Meanwhile, a further variation in concentration from $12.4 \%$ to $29.8 \%$ has led to a small modification in the $E_{a b s}(1.88-1.76 \mathrm{eV})$, that is only $0.12 \mathrm{eV}$. This nonlinearity may be due to trends toward a saturated interaction (in terms of the available geometrical positions) between the chains of DH6T host and aggregated molecular ligands of Alq3. Upon adding higher concentrations (above $29.8 \%$ ) of Alq3, the value of the absorption edge energy started to rise and larger values of $E_{a b s}$ are produced. This may be because of the appearance of predominated Alq3 ligands over the DH6T chains, as Alq3 corresponds to higher $E_{a b s}$ (of about $2.86 \mathrm{eV}$ [21]) compared to that of the DH6T host $(2.69 \mathrm{eV})$.

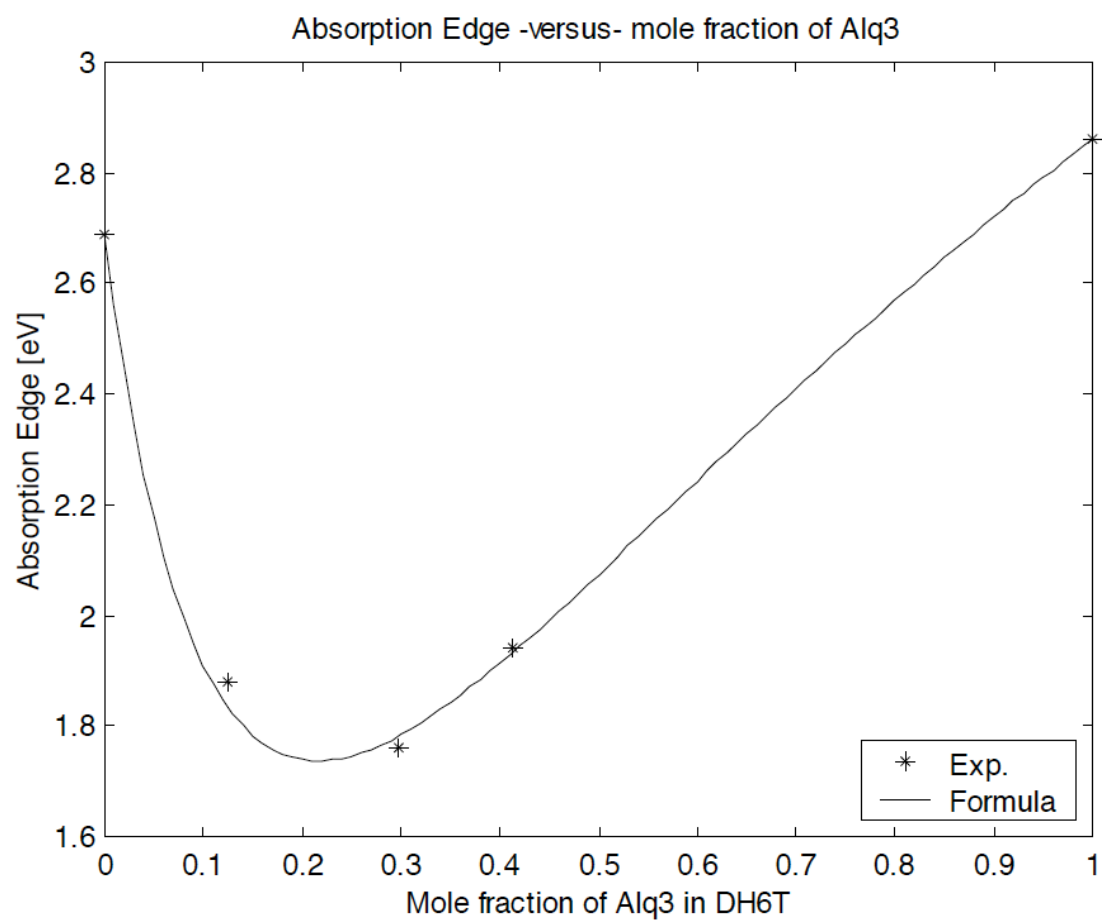

Figure 4: Absorption edge energy versus molar concentration of Alq3 in DH6T. 


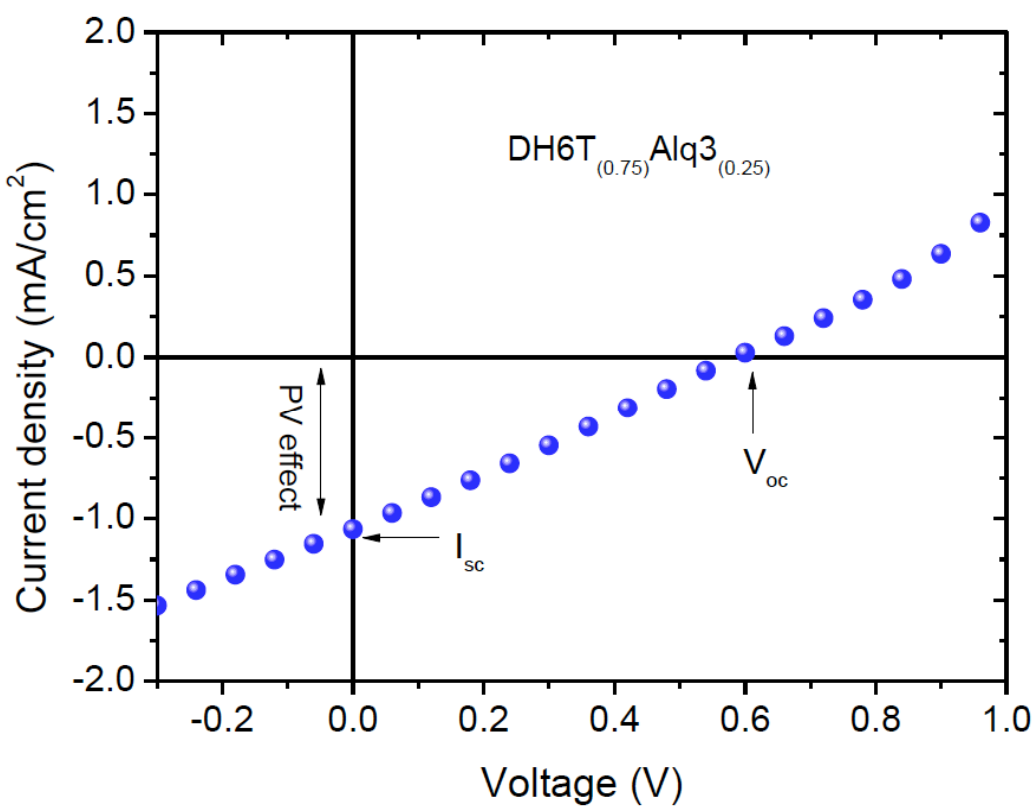

Figure 5: $\mathrm{J}-\mathrm{V}$ characteristic of organic solar cells based on $\mathrm{DH} \mathrm{T}_{(0.75)} \mathrm{Alq} 3_{(0.25)}$.

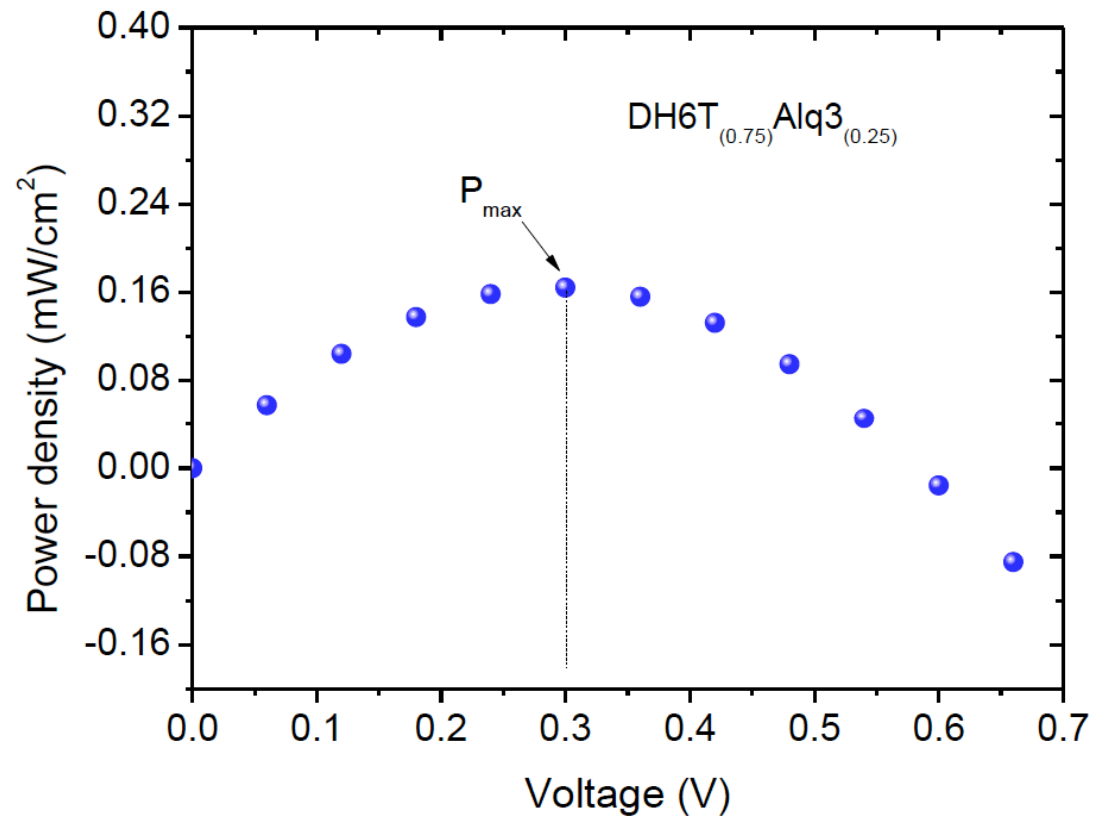

Figure 6: $P-V$ characteristic of organic solar cells based on $\mathrm{DH} \mathrm{T}_{(0.75)} \mathrm{Alq}_{(0.25)}$.

Figures 5 and 6 show the current-voltage and power-voltage characteristics of organic solar cells based on $\mathrm{DH}_{6 \mathrm{~T}} \mathrm{~T}_{(0.75)} \mathrm{Alq} 3_{(0.25)}$, respectively. The results showed a significant photovoltaic (PV) activity upon illumination of the solar cells with white light. It was found that the short circuit current density, $J_{s c}$ (current when the solar cell terminals are shorted under light) is about $1.07 \mathrm{~mA} / \mathrm{cm}^{2}$, while the open circuit voltage, $V_{o c}$ (voltage when the solar cell terminals are open under light) is equal to $0.6 \mathrm{~V}$. Consequently, the maximum power capable to be delivered by the solar cell to an external load was found to be $0.17 \mathrm{~mW} / \mathrm{cm}^{2}$. This power can be extracted only when the load resistance is equal to the internal resistance of the cell. Further analysis on the photovoltaic performance was done through determination of the cells efficiency and fill factor. These were calculated by using the following equations:

$$
\eta=\frac{P_{\max }}{P_{\text {in }}} \times 100
$$




$$
F F=\frac{P_{\max }}{I_{S C} \times V_{o c}} \times 100
$$

Where, $P_{\text {in }}$ is the light power strikes the active area of the cell, and it was equal to $80 \mathrm{~mW} / \mathrm{cm}^{2}$ in the current study. Fill factor is a geometrical measure of the output performance of solar cells, which is considered as the ratio of $J-V$ area at the $P_{\text {max }}$ to the $J_{s c}$ $\times V_{o c}$ area. Efficiency and fill factor for the investigated solar cells based on $\mathrm{DH} \mathrm{T}_{(0.75)} \mathrm{Alq}_{(0.25)}$ active layer was found to be $0.22 \%$ and $26.5 \%$, respectively. The results showed that photovoltaic performance in the DH6T:Alq3 based devices is much better than that achieved for the DH6T:PCBM based ones [30]. Comparably, the efficiency and fill factor of DH6T:PCBM based devices were found to be $0.01 \%$ and $24 \%$, respectively. Interestingly, the device performance obtained in the current study can be further enhanced by means of optimizing the active layer thickness [31], device architecture [32] and annealing process [33], suggesting that DH6T:Alq3 based organic solar cells can be a promising candidate in the field of solution processable organic solar cells.

\section{CONCLUSIONS}

Films of $\mathrm{DH6T}_{(1-x)} \mathrm{Alq}_{(x)}$ composite containing controlled amount of Alq3 were successfully prepared from solutions to investigate the effect of Alq3 admixture with $\mathrm{DH} 6 \mathrm{~T}$ on their absorption edge energy $E_{a b s}$. The value of $E_{a b s}$ at the fundamental light absorption in the wavelength range of $250-2500 \mathrm{~nm}$ $(4.97 \mathrm{eV}-0.50 \mathrm{eV})$ has been deduced via the optical absorption measurement. This work indicates that the $E_{a b s}$ of DH6T can be tuned from $2.69 \mathrm{eV}$ to $1.76 \mathrm{eV}$ upon introducing Alq3 with concentration from $0 \%$ to $\sim 30 \%$. The tuneability of $E_{a b s}$ will have an impact on the designation of optoelectronic and electronic devices such as Organic Light Emitting Diodes (OLED)s, Organic Solar Cells (OSC)s and Organic Field Effect Transistors (OFET)s. An empirical formula has been suggested to fit the variation of the absorption edge in $\mathrm{DH}_{6} \mathrm{~T}_{(1-\mathrm{x})} \mathrm{Alq}_{(\mathrm{x})}$ composites with Alq3 concentration, as it can be used as a tool for further studies and/or fabricating devices by adding the identified Alq3 concentration to achieve the required $E_{a b s}$. In the range of photon energies covered in this work, three subregions are discerned; each with its own absorption edge. We have explained the results in terms of exciton levels, molecular interaction, and predominance of one component over the other.

\section{ACKNOWLEDGEMENTS}

We thank University of Malaya for providing the research grants under PS319/2009B and RG053/09AFR to support this research work.

\section{CONFLICT OF INTERESTS}

The authors declare that there is no conflict of interests regarding the publication of this article.

\section{REFERENCES}

[1] Shirota Y. Organic materials for electronic and optoelectronic devices. Journal of Materials Chemistry 2000; 10: 1-25. http://dx.doi.org/10.1039/a908130e

[2] Narasimharaghavan PK, Yadav H, Varadarajan TS, Patnaik LN, Das S. Organic photoconductors: Dark and photoconduction studies in two p-dimethylamino styryl dyes derived from pyridine- 2 and pyridine- 4 . Journal of Materials Science $1991 ; 26:$ 4774-86. http://dx.doi.org/10.1007/BF00612417

[3] Nelson J. Organic photovoltaic films. Materials Today 2002; 5: 20-7.

http://dx.doi.org/10.1016/S1369-7021(02)05532-3

[4] Kim K, Liu J, Namboothiry MAG, Carroll DL. Roles of donor and acceptor nanodomains in $6 \%$ efficient thermally annealed polymer photovoltaics Applied Physics Letters 2007; 90: 163511 .

http://dx.doi.org/10.1063/1.2730756

[5] Fraboni B, DiPietro R, Cavallini A, Cosseddu P, Bonfiglio A Vogel J. Photocurrent studies of sexythiophene-based OFETs. Applied Physics A: Materials Science and Processing 2009; 95: 37-41. http://dx.doi.org/10.1007/s00339-008-4998-9

[6] Iosip MD, Destri S, Pasini M, Porzio W, Pernstich KP Batlogg B. New dithieno[3,2-b: 2',3'-d]thiophene oligomers as promising materials for organic field-effect transistor applications. Synthetic Metals 2004; 146: 251-7. http://dx.doi.org/10.1016/i.synthmet.2004.08.004

[7] Nguyen PT, Rammelt U, Plieth W, Richter S, Plötner M, Fischer WJ, et al. Experiments with organic field effect transistors based on polythiophene and thiophene oligomers. Electrochimica Acta 2005; 50: 1757-63. http://dx.doi.org/10.1016/j.electacta.2004.10.062

[8] Sakai J, Taima T, Saito K. Efficient oligothiophene: fullerene bulk heterojunction organic photovoltaic cells. Organic Electronics 2008; 9: 582-90.

http://dx.doi.org/10.1016/j.orgel.2008.03.008

[9] Veenstra SC, Malliaras GG, Brouwer HJ, Esselink FJ, Krasnikov VV, van Hutten PF, et al. Sexithiophene- $C_{60}$ blends as model systems for photovoltaic devices. Synthetic Metals 1997; 84: 971-2. http://dx.doi.org/10.1016/S0379-6779(96)04235-X

[10] Ye R, Baba M, Suzuki K, Mori K. Fabrication of highly airstable ambipolar thin-film transistors with organic heterostructure of $\mathrm{F}_{16} \mathrm{CuPc}$ and $\mathrm{DH}-\mathrm{a} 6 \mathrm{~T}$. Solid-State Electronics 2008; 52: 60-2. http://dx.doi.org/10.1016/.j.sse.2007.07.010

[11] Loussaïef N, Kouki F, Delannoy P, Garnier F, Hassine L, Bouchriha $\mathrm{H}$. Transient photocurrent in sexithiophene-based photovoltaic cells. Materials Science and Engineering: C 2002; 21: 255-8.

http://dx.doi.org/10.1016/S0928-4931(02)00076-0 
[12] Horowitz G, Romdhane S, Bouchriha H, Delannoy P, Monge $\mathrm{J}$-L, Kouki F, et al. Optoelectronic properties of sexithiophene single crystals. Synthetic Metals 1997; 90: 187-92. http://dx.doi.org/10.1016/S0379-6779(98)80005-2

[13] Tavazzi S, Barbarella G, Borghesi A, Meinardi F, Sassella A, Tubino R. Absorption coefficient of sexithiophene thin films grown by organic molecular beam deposition. Synthetic Metals 2001; $121: 1419-20$. http://dx.doi.org/10.1016/S0379-6779(00)01141-3

[14] Wu MW, Conwell EM. Transport in [alpha]-sexithiophene films. Chemical Physics Letters 1997; 266: 363-7. http://dx.doi.org/10.1016/S0009-2614(97)00022-5

[15] Yakuphanoglu F. Electrical conductivity and electrical modulus properties of [alpha], [omega]-dihexylsexithiophene organic semiconductor. Physica B: Condensed Matter 2007; 393: $139-42$

http://dx.doi.org/10.1016/j.physb.2006.12.075

[16] Knupfer M, Liu X. Interface electronic properties of oligothiophenes: the effect of chain length and chemical substituents. Surface Science 2006; 600: 3978-81. http://dx.doi.org/10.1016/..susc.2006.01.110

[17] Liu X, Knupfer M, Huisman BH. Electronic properties of the interface between [alpha],[omega]-dihexyl-quaterthiophene and gold. Surface Science 2005; 595: 165-71. http://dx.doi.org/10.1016/..susc.2005.08.007

[18] Murphy AR, Fréchet JMJ, Chang P, Lee J, Subramanian V. Organic Thin Film Transistors from a Soluble Oligothiophene Derivative Containing Thermally Removable Solubilizing Groups. Journal of the American Chemical Society 2004; 126: 1596-7. http://dx.doi.org/10.1021/ja039529x

[19] Sato T, Fujitsuka M, Segawa H, Shimidzu T, Tanaka K. Dual photoluminescence of polythiophene thin films. Synthetic Metals 1998; 95: 107-12. http://dx.doi.org/10.1016/S0379-6779(98)00040-X

[20] Xiao L, Liu Y, Xiu Q, Zhang L, Guo L, Zhang H, et al. Novel polymeric metal complexes as dye sensitizers for Dyesensitized solar cells based on poly thiophene containing complexes of 8-hydroxyquinoline with $\mathrm{Zn}$ (II), $\mathrm{Cu}$ (II) and Eu(III) in the side chain. Tetrahedron 2010; 66: 2835-42. http://dx.doi.org/10.1016/j.tet.2010.02.039

[21] Muhammad FF, Abdul Hapip Al, Sulaiman K. Study of optoelectronic energy bands and molecular energy levels of tris (8-hydroxyquinolinate) gallium and aluminum organometallic materials from their spectroscopic and electrochemical analysis. Journal of Organometallic Chemistry 2010; 695: 2526-31. http://dx.doi.org/10.1016/j.jorganchem.2010.07.026

[22] Aziz SB. Modifying Poly (Vinyl Alcohol)(PVA) from Insulator to Small-Bandgap Polymer: A Novel Approach for Organic
Solar Cells and Optoelectronic Devices. Journal of Electronic Materials: 1-10.

[23] Aziz SB, Ahmed HM, Hussein AM, Fathulla AB, Wsw RM, Hussein RT. Tuning the absorption of ultraviolet spectra and optical parameters of aluminum doped PVA based solid polymer composites. J Mater Sci: Mater Electron 2015; 26: 8022-8.

http://dx.doi.org/10.1007/s10854-015-3457-6

[24] Muhammad FF, Aziz SB, Hussein SA. Effect of the dopant salt on the optical parameters of PVA: NaNO3 solid polymer electrolyte. J Mater Sci: Mater Electron 2014; 26: 521-9. http://dx.doi.org/10.1007/s10854-014-2430-0

[25] Afzali A, Breen TL, Kagan CR. An Efficient Synthesis of Symmetrical Oligothiophenes: Synthesis and Transport Properties of a Soluble Sexithiophene Derivative. Chemistry of Materials 2002; 14: 1742-6. http://dx.doi.org/10.1021/cm011528I

[26] Muhammad FF, Sulaiman K. Utilizing a simple and reliable method to investigate the optical functions of small molecular organic films - Alq3 and Gaq3 as examples. Measurement 2011; 44: 1468-74.

http://dx.doi.org/10.1016/j.measurement.2011.05.017

[27] Abay B, Güder HS, Efeoglu H, Yogurtçu YK. Excitonic absorption and Urbach-Martienssen's tails in Er-doped and undoped n-type InSe. Journal of Physics D: Applied Physics 1999; 32: 2942. http://dx.doi.org/10.1088/0022-3727/32/22/317

[28] Kittel C. Introduction to solid state physics: Wiley; 2005.

[29] Bouarissa N. Pseudopotential calculations of Cd1-xZnxTe: Energy gaps and dielectric constants. Physica B: Condensed Matter 2007; 399: 126-31 http://dx.doi.org/10.1016/j.physb.2007.05.034

[30] Muhammad FF, Sulaiman K. Photovoltaic performance of organic solar cells based on DH6T/PCBM thin film active layers. Thin Solid Films 2011; 519: 5230-3. http://dx.doi.org/10.1016/j.tsf.2011.01.165

[31] Jin S-H, Vijaya Kumar Naidu B, Jeon H-S, Park S-M, Park J$\mathrm{S}$, Chul Kim S, et al. Optimization of process parameters for high-efficiency polymer photovoltaic devices based on P3HT: PCBM system. Solar Energy Materials and Solar Cells 2007; 91: 1187-93. http://dx.doi.org/10.1016/j.solmat.2007.04.001

[32] Muhammad FF. Design approaches to improve organic solar cells. Journal of Technology Innovations in Renewable Energy 2014; 3: 1-8. http://dx.doi.org/10.6000/1929-6002.2014.03.02.4

[33] Sakai J, Taima T, Yamanari T, Saito K. Annealing effect in the sexithiophene: $\mathrm{C}_{70}$ small molecule bulk heterojunction organic photovoltaic cells. Solar Energy Materials and Solar Cells 2009; 93: 1149-53. http://dx.doi.org/10.1016/j.solmat.2009.02.007 